\title{
Wheat Yield in a Tolerant Winter Wheat Line Infested by Hessian Fly (Mayetiola destructor)
}

\author{
Kirsten E. Roe', Brandon J. Schemerhorn ${ }^{1,2^{*}}$ \\ ${ }^{1}$ Department of Entomology, Purdue University, West Lafayette, Indiana, USA \\ ${ }^{2}$ USDA-ARS, Crop Production and Pest Control Research Unit, West Lafayette, Indiana, USA \\ Email: ^brandi.schemerhorn@usda.gov
}

How to cite this paper: Roe, K.E. and Schemerhorn, B.J. (2021) Wheat Yield in a Tolerant Winter Wheat Line Infested by Hessian Fly (Mayetiola destructor). Advances in Entomology, 9, 70-84.

https://doi.org/10.4236/ae.2021.92007

Received: October 1, 2020

Accepted: April 5, 2021

Published: April 8, 2021

Copyright (c) 2021 by author(s) and Scientific Research Publishing Inc. This work is licensed under the Creative Commons Attribution International License (CC BY 4.0).

http://creativecommons.org/licenses/by/4.0/

(c) (i) Open Access

\begin{abstract}
The Hessian fly, Mayetiola destructor, is a harmful pest of wheat (Triticum aestivum). Pioneer variety $25 \mathrm{R} 78$ is putatively tolerant, meaning that the plant can survive successful Hessian fly infestation with reduced growth effects. To understand if Hessian fly-tolerance in wheat results in reduced yield effects and to analyze the economic feasibility of tolerant wheat as a Hessian fly control method, this study focused on analyzing the effect of infestation on tolerant wheat yield. This study analyzed tolerant Pioneer variety 25R78, resistant Pioneer brand variety 25R32, and susceptible Pioneer brand variety 25R47 through harvest. Treated plants were infested using a plastic cover and allowing 1 - 2 female flies to lay eggs for two hours. We measured head, fertile head number and tiller number. Seeds were analyzed by measuring total seed number and weight, as well as average seed number and weight. Tolerant and resistant plants showed no significant effects on yield in comparison to susceptible wheat. The infested tolerant plants were comparable in yield to infested resistant plants. Therefore, we propose that tolerance incorporated into wheat varieties will lower selection pressure on Hessian fly populations and increase the durability of these wheat lines.
\end{abstract}

\section{Keywords}

Mayetiola destructor, Tolerance, Resistance, Virulence, Yield

\section{Introduction}

Wheat (Triticum aestivum) is the most globally consumed cereal crop, with an estimated production of 749.3 million tonnes in 2016-2017 (FAO, 2016). Threats to wheat yield and production are an important area of research, due to wheat's importance in food security. Bread wheat is a valuable crop, making up the 
greatest source of food calories and being the most widely cultivated crop [1]. Unfortunately, the Hessian fly, or Mayetiola destructor (Say) (Diptera: Cecidomyiidae), is one of the leading contributors to wheat yield loss. Hessian fly infestations can lead to losses of up to $\$ 100$ million per year in the United States as reported in 1953, a converted value of approximately $\$ 886$ million per year [2]. The Hessian fly range includes the wheat-growing regions of North America, Europe, and North Africa [3] [4] [5]. While no North American studies have been done to evaluate percentage of crop loss, in Morocco, heavy infestations have been shown to cause can cause 32\% - 100\% yield loss [4] [6] [7].

Unlike most fellow members of the gall midge family (Cecidomyiidae), Hessian flies induce nutritive tissue at a feeding site rather than a normal gall, feeding at the site for 10 - 14 days [5] [8] [9]. In compatible interactions, epidermal and mesophyll cells at the feeding site accumulate organelles and free amino acids, cell walls thin, and cells rupture, releasing nutrients for the larva to ingest [10]. Larval feeding permanently stunts plants, reduces stem elongation, prevents nutrient allocation to the developing grain head, and can kill the plant [11] [12].

In incompatible interactions caused by plant resistance genes, feeding sites fail to form and larvae die after 3 - 5 days [10] [13] [14] [15]. Thirty-five identified resistance genes are currently the primary method of Hessian fly control and research [16] [17] [18]. R genes confer plant resistance to Hessian fly by recognizing secreted effectors from avirulent larvae. Then, the plant defense response, called effector-triggered immunity, occurs, triggering an up-regulation of the gene encoding Hfr-1. This protein is a plant lectin that might affect the avirulent larva's ability to feed by preventing the establishment of a successful feeding site and causing the larvae to experience writhing and increased searching time [19].

However, the lethal larval antibiosis places selection pressures on surviving fly populations, leading to an increased frequency of virulent biotypes that are capable of overcoming resistance genes. These virulent flies act similarly to flies on susceptible wheat, leading to stunted plants, yield loss, or plant death. This leads to the question of whether there is another method of managing Hessian flies which would either reduce selection pressures or increase the longevity of resistance genes. Can wheat plants survive infestation and not kill the feeding larvae?

One possible solution would be to combine the ability to survive initial infestation and the inability to kill the larvae, thus potentially reducing or eliminating selection pressures on fly populations caused by resistance genes. This might be possible with tolerance in wheat to Hessian fly damage. In the context of insect herbivory, tolerance has been defined several ways. These definitions include the ability for a plant to recover, grow, and potentially reproduce despite pest attack, without placing selection pressures on the pest populations and the ability to tolerate damage which minimizes yield effects caused by pests without killing the pests [20] [21] [22].

A benefit of tolerance is that it can support and maintain natural enemy populations by not decreasing prey numbers through antixenosis (non-preference) 
or antibiosis. Tolerance could also increase economic injury levels, known as the smallest number of pests to cause economic damage, through reducing the amount of damage caused by each insect. This might reduce or delay required insecticide use [20]. Tolerance does not impose selection pressures that lead to the formation of novel biotypes, unlike insecticides or resistance genes [20] [21]. The absence of selection pressure is due to tolerance being a plant reaction to insect attack without direct effect on insect physiology, growth, reproduction, biology, or fitness making tolerance more evolutionarily stable than defense such as antibiosis [20].

The only research on wheat tolerance response to Hessian flies has been through indirect research on partial tolerance. One of the first proposed partially tolerant lines was the Marquillo hybrid. Marquillo hybrids, a cross of $R$ gene H18-containing Marquillo and winter wheat, were able to survive and provide yield even under heavy infestation of Hessian fly infestation (Agricultural Experiment Station Kansas State 1940).

Another partially tolerant line is the "Superb" line. The wheat line "Superb" can reduce yield loss from fly infestations by up to $65 \%$ compared to susceptible lines such as "AC Barrie" due to the partial tolerance and antibiosis present in the line [23] [24]. These researchers considered tolerance as the ability of wheat stems to survive larval feeding without snapping [23]. "Superb" showed partial larval death which could place selection pressure on fly populations. Pioneer variety 25R78 was screened by Sue Cambron in the USDA-ARS greenhouse in West Lafayette, IN. The screening showed potential tolerance in that flies continued to emerge from the plants after infestation, but plants did not die or stunt as dramatically. To investigate this potential tolerance, we tested Pioneer variety 25R78 was chosen as the putative tolerant line to be studied in this experiment. The susceptible Pioneer variety $25 \mathrm{R} 75$ was chosen to act as a control for this tolerant line.

Theoretically, tolerance in wheat might be used alongside resistance to help offset allocation expenses for $R$ genes such as reduced yield, seed protein, and seed weight [19] [25]. Initially, there might be an allocation cost for a resistant and tolerant plant, but increased growth would eventually compensate for this cost [25]. This compensation could be completed via carbon deployment to larvae-inaccessible regions or subsequent redistribution of the carbon for growth [19].

In addition to previous studies, there are multiple reasons why tolerance to Hessian flies may to be present in wheat. Susceptible "Newton" can trigger growth through tiller production from an axillary coleoptile meristem to survive infestation, despite costs in yield production [10]. Second, some infested resistant lines reflect growth compensation through the production of superior qualities compared to uninfested plants such as greater seed and head numbers and heads as well greater height. For example, infested $H 6$ plants were taller, $H 13$ plants had a greater number of seeds and greater total seed weights, and $H 9$ and 
H13 plants had more seed heads compared to susceptible lines [25].

However, Hessian fly tolerance might not only be present partially in resistant and susceptible wheat lines but could be a unique plant response allowing the plant to survive and produce yield without directly harming the larvae. We investigated if the putative tolerant Pioneer ${ }^{\otimes}$ brand variety Pioneer variety 25R78 could grow to successfully produce yield without directly killing the larvae via antibiosis. We also asked whether tolerant plants stunt and recover or stunt to the point of reducing yield. If yield is unaffected, this would potentially prevent yield and economic loss from Hessian fly infestations while not killing the flies and creating virulent biotypes.

\section{Materials and Methods}

\subsection{Plant and Insect Preparation}

To determine effects of Hessian fly infestation on tolerant lines, we compared three different lines. The lines used were susceptible Pioneer brand variety 25R47, tolerant Pioneer brand variety 25R78, and resistant Pioneer brand variety 25R32. Each line had an infested treatment and an uninfested control. The planting was staggered across subsequent days with 25R32, 25R47, and 25R78 planted in that order. In a greenhouse, square pots $(3.10 \mathrm{~cm} \times 3.10 \mathrm{~cm} \times 2.33$ $\mathrm{cm}$, Traditional Inserts, and 18 pots/packs per insert) were filled with soil to within $2.54 \mathrm{~cm}$ of the rim. Water was added and the soil was mixed until no dry soil remained. After the pots drained, one seed was planted for each pot and gently pressed into the soil. Twenty-six seeds were planted for each line and treatment ( 6 sets total). More soil was mixed with water and $1 \mathrm{~cm}$ of this soil was added to each pot over the seed. Each pot was watered twice with water to the rim, then watered with a solution of $2300 \mathrm{~mL}$ and $5.48 \mathrm{~g}$ of fertilizer (Scotts General Purpose, 20:20:20). The pots remained in the greenhouse at $19^{\circ} \mathrm{C}( \pm$ $5^{\circ} \mathrm{C}$ ) under metal halide lamps ( $\mathrm{Hg}$; irradiance level $140 \mu \mathrm{mol} \cdot \mathrm{m}^{-2} \cdot \mathrm{s}^{-1}$ ) set at a photoperiod of 12 hours for 11 days after planting with watering as needed.

For the infested plants, Hessian fly biotype E was used. This biotype is avirulent on H3 (Monon) and was maintained by Sue Cambron at the USDA-ARS Crop Production and Pest Control Research Unit, Purdue University. The flies were maintained in a $4^{\circ} \mathrm{C}$ cold storage unit. Wheat material with puparia was removed from the unit and placed in a clear plastic box $(26$ by $39 \mathrm{~cm})$, moistened with water, and kept under fluorescent lights at $18^{\circ} \mathrm{C}$ for 11 days.

\subsection{Plant Infestation}

For comparisons between infested and control plants, treated plants were infested with Hessian flies. First, after 11 days when the plants were at the 2- to 3leaf stage, the pots were brought into the lab and measurements were taken. Then, the plants were covered with plastic covers ( $24 \mathrm{oz}$ Meijer brand water bottles). These covers had $2.54 \mathrm{~cm}$ of the bottom removed, a hole $(2.54 \mathrm{~cm}$ diameter) cut on the side, and mesh hot-glued to the top (with the lid removed). One 
mated female fly was placed with an aspirator in each cover and a Styrofoam plug was placed in the hole. Flies remained for 6 hours and were then removed. Egg numbers were counted and any plants in the treatment group that had no eggs or larvae present were removed from the analysis.

The pots were kept inside under a fluorescent light at $80 \%( \pm 5 \%)$ humidity for 5 days. On the $5^{\text {th }}$ day, the covers were removed and the pots were placed in the growth chamber at $16^{\circ} \mathrm{C}\left( \pm 2^{\circ} \mathrm{C}\right)$ with a photoperiod of $16: 8$ (day:night). Irradiance levels in the growth chamber were approximately $650-700 \mu \mathrm{mol} \cdot \mathrm{m}^{-2} \cdot \mathrm{s}^{-1}$. Each pot was watered with $200 \mathrm{~mL}$ tap water 4 - 5 days per week. The pots were each watered for 4 seconds after 16 days in the growth chamber with a solution of $2300 \mathrm{~mL}$ and $5.48 \mathrm{~g}$ of fertilizer (Scotts General Purpose, 20:20:20). The plants remained in the growth chamber for 35 days. The pots were randomly placed in groups of six within the chamber. Each group of six had one pot for each factor level (i.e. one pot from each line and for both treatments). At the 16-day mark, they were watered with fertilizer water as above. After 35 days, the plants were placed in a cold storage unit (Bally) for 64 days $\left(4^{\circ} \mathrm{C}\right)$. Watering occurred 1 - 2 times a week as needed. Every plant was sprayed as needed with fungicide to treat powdery mildew.

\subsection{Plant Transplant}

For the plants to have sufficient space to produce roots and seeds, the plants were moved to larger pots. First, after 65 days, the plants were placed in a growth chamber (Revco Honeywell, $16^{\circ} \mathrm{C}, 80 \%$ humidity) for 15 days. Then, the plants were placed in a greenhouse for 29 days. Chambers were placed over the plants after 24 days to catch emerging adult flies. After 5 days, the chambers were removed and each plant was transferred to an individual pot $(15.24 \mathrm{~cm}$ diameter, $15.24 \mathrm{~cm}$ deep) with moist soil. The moist soil was previously mixed in each pot so that it reached to within $10 \mathrm{~cm}$ of the rim. A large scoop of soil was removed in the center, forming a valley $10 \mathrm{~cm}$ across and $25 \mathrm{~cm}$ in depth, and $7-10$ fertilizer pellets were placed in a $3 \mathrm{~cm}$ diameter circle in the hollow.

Additional soil was placed on top until it reached a height of $1.5 \mathrm{~cm}$ as measured by a ruler. The soil was then pressed down, forming a flat surface. The plant, roots, and soil were removed from each square pot and placed gently in the hole left in the new pot. Moist soil was placed around the sides of the plant to fill in any spaces. The plant was watered with tap water twice. For the next 12 weeks, plants were watered 5 days a week with $200 \mathrm{~mL}$ of water. For the last 3 weeks, plants were watered 3 days a week and treated with insecticide (Ortho Flower, Fruit \& Vegetable) for aphid control. Each line was harvested 15 weeks after transplanting.

\subsection{Measurements Taken}

The following measurements allowed for an initial understanding of tolerance in wheat. The measurements used were modeled after the research on the fitness 
costs of $\mathrm{H}$-gene mediated resistance in wheat to Hessian flies [25]. The measurements recorded included the following for each plant: plant survival, head number, fertile head number, seed number, seed weight, and tiller number. The fertile head number included only the heads with seeds. Seed weight was measured using a scale (College B303-S, Mettler Toledo). The seeds for each individual head were placed together on a piece of circular filter paper (Whatman, 12.5 $\mathrm{cm}$, Grade 5). Average seed number was calculated by taking the average of the seed numbers from each head of a plant. The same was done for average seed weight. Total seed number and weight were taken by finding the sum of either the count or weight of all seeds from a plant.

\subsection{Statistical Analysis}

To determine effects of infestation on the three lines, statistical analyses were performed in R (R Core Team 2014). The design was a two-way factorial with the following levels: 1) infested 25R32, 2) uninfested 25R32 as control, 3) infested 25R47, 4) control uninfested 25R47, 5) infested Pioneer variety 25R78, and 6) uninfested control Pioneer variety 25R78. The sample sizes for the different levels were the following: control Pioneer variety 25R78 $(n=24)$, treated Pioneer variety $25 R 78(\mathrm{n}=27)$, control 25R47 $(\mathrm{n}=27)$, treated 25R47 $(\mathrm{n}=16)$, control 25R32 $(\mathrm{n}=28)$, and treated 25R32 $(\mathrm{n}=26)$. Differences in sample size were due to uneven germination and the absence of successful infestation for several plants. A statistical significance threshold of $=0.05$ was used.

Seed number and seed weight was continuous variables with a normal distribution while head, fertile head, and tiller numbers were integer ratio scale variables. Each of these variables was analyzed using a two-way ANOVA, using the aov function of package in the base R package (R Core Team 2014). Plant survival was a categorical variable, analyzed using a two-way Chi-square test in base R package.

\section{Results}

\subsection{Heads and Fertile Heads Number}

The results indicated that there was no significant effect from infestation on head number for either resistant with a p-value of 0.790 (Figure 1) or tolerant plants $(\mathrm{P}=0.999)$. However, infested susceptible Pioneer variety $25 \mathrm{R} 47$ was significantly smaller than the uninfested plants $(P=0.006)$. There was no significant difference in head number between infested tolerant plants and infested Pioneer variety $25 \mathrm{R} 47$ plants as well as infested Pioneer variety 25R32 plants ( $\mathrm{P}$ $=0.999$ and $\mathrm{P}=0.994$, respectively) (Table 1 ).

Infestation did not significantly decrease the number of fertile heads for resistant $(\mathrm{P}=0.864$; Figure 2$)$ or tolerant plants $(\mathrm{P}=0.999)$ as well. However, infested susceptible Pioneer variety 25R47 was significantly smaller than the uninfested plants $(\mathrm{P}=0.006)$. There was no significant difference in head number between infested tolerant plants and infested Pioneer variety 25R47 plants as 


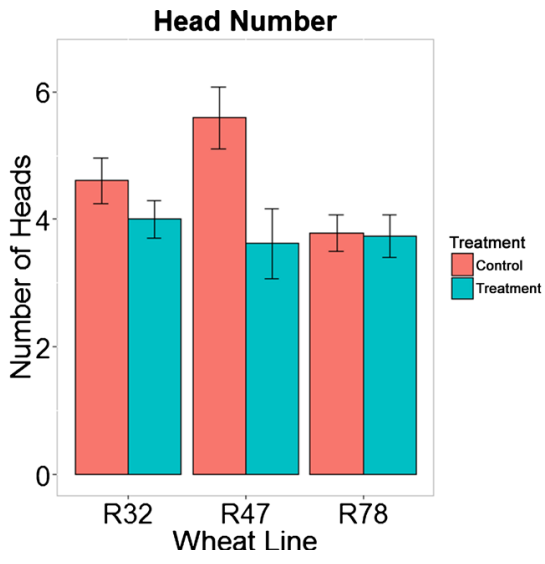

Figure 1. Relationship between head number, wheat line, and treatment. Wheat lines: resistant 25R32 (R32), susceptible Pioneer variety 25R47 (R47), and tolerant Pioneer variety 25 R78 (R78) when infested (blue) and uninfested (pink). Error bars represent standard errors of each sample.

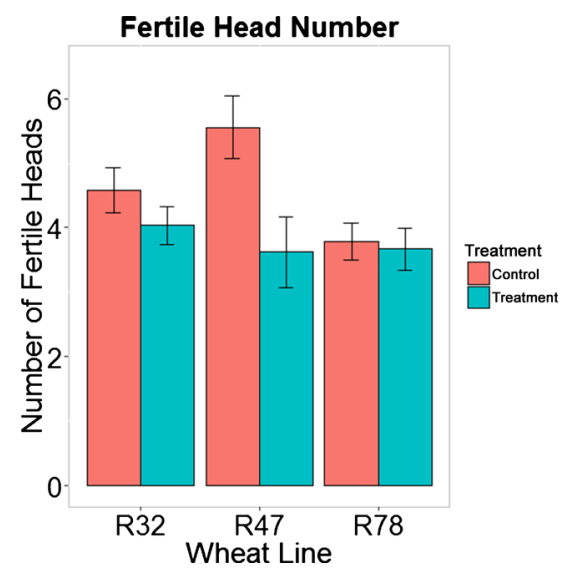

Figure 2. Relationship between fertile head number, wheat line, and treatment. Wheat lines: resistant 25R32 (R32), susceptible Pioneer variety 25R47 (R47), and tolerant Pioneer variety 25R78 (R78) when infested (blue) and uninfested (pink). Error bars represent standard errors of each sample.

Table 1. Post-hoc Tukey analysis on head number and tiller number.

\begin{tabular}{ccc}
\hline Measurement & Wheat Line & P value \\
\hline Head Number & $25 R 78-25 R 47$ & 0.994 \\
& $25 R 78-25 R 32$ & 0.999 \\
Tiller Number & $25 R 78-25 R 47$ & 0.974 \\
& $25 R 78-25 R 32$ & 0.912 \\
\hline
\end{tabular}

${ }^{*}$ Significant at $\mathrm{P} \leq 0.05 .{ }^{*}$ Significant at $\mathrm{P} \leq 0.01 .{ }^{* *}$ Significant at $\mathrm{P} \leq 0.001$.

well as infested Pioneer variety 25R32 plants $(\mathrm{P}=0.999$ and $\mathrm{P}=0.969$, respectively) (Table 2).

\subsection{Tiller Number}

Infestation did not significantly decrease tiller numbers for resistant $(\mathrm{P}=0.935$; 
Figure 3) or tolerant plants ( $\mathrm{P}=0.898$; Figure 3$)$. However, infested susceptible Pioneer variety $25 \mathrm{R} 47$ was significantly smaller than the uninfested plants $(\mathrm{P}=$ 0.015). There was no significant difference in head number between infested tolerant plants and infested Pioneer variety 25R47 plants or infested Pioneer variety 25R32 plants $(\mathrm{P}=0.974$ and $\mathrm{P}=0.912$, respectively) (Table 2$)$.

\subsection{Total Seed Number and Weight}

Hessian fly infestation did not significantly decrease total seed number for resistant or tolerant plants $(\mathrm{P}=0.678$ and $\mathrm{P}=0.993$, respectively; Figure 4). However, infested susceptible Pioneer variety $25 \mathrm{R} 47$ had significantly fewer seeds than the uninfested plants $(\mathrm{P}=0.007)$. There was no significant difference in total seed number between infested tolerant plants and infested Pioneer variety 25R32 plants or infested Pioneer variety 25R47 plants $(\mathrm{P}=0.933$ and $\mathrm{P}=0.492$, respectively) (Table 3).

Table 2. Effects of treatment and wheat line, and their interaction on the number of wheat heads, fertile heads, and tiller number as determined by two-way ANOVA.

\begin{tabular}{ccccccc}
\hline Measurement & & F-value & Df & P-value & Sum Sq. & Mean Sq. \\
\hline \multirow{2}{*}{ Head Number } & Treatment & 9.650 & 1 & $0.002^{* *}$ & 28.80 & 28.82 \\
& Line & 3.657 & 2 & $0.028^{*}$ & 21.80 & 10.92 \\
& Treatment:Line & 3.570 & 2 & $0.031^{*}$ & 21.30 & 10.66 \\
Fertile Head & Treatment & 9.548 & 1 & $0.002^{* *}$ & 28.10 & 28.12 \\
Number & Line & 3.877 & 2 & $0.023^{*}$ & 22.80 & 11.41 \\
& Treatment:Line & 3.323 & 2 & $0.039^{*}$ & 19.60 & 9.786 \\
Tiller Number & Treatment:Line & 2.158 & 2.142 & 0.119 & 14.70 & 7.340 \\
& Treatment & 11.48 & 1.142 & $<0.001^{* * *}$ & 39.00 & 39.04 \\
& Line & 5.372 & 2.142 & $0.006^{* *}$ & 36.50 & 18.27 \\
\hline
\end{tabular}

${ }^{\star}$ Significant at $\mathrm{P} \leq 0.05 .{ }^{*}$ Significant at $\mathrm{P} \leq 0.01 .{ }^{* *}$ Significant at $\mathrm{P} \leq 0.001$.

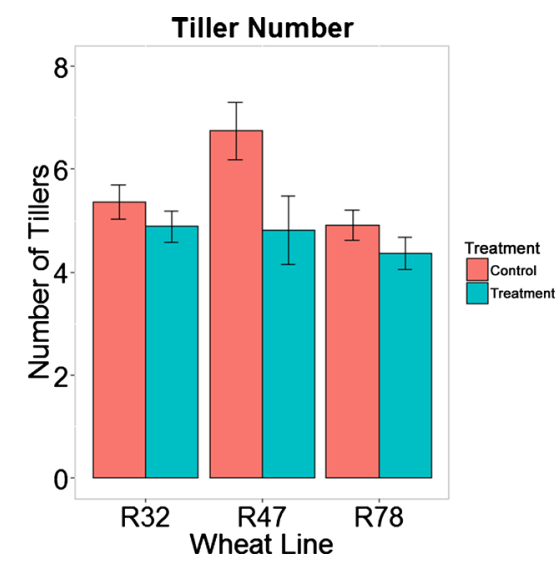

Figure 3. Relationship between tiller number, wheat line, and treatment. Wheat lines: resistant 25R32 (R32), susceptible Pioneer variety 25R47 (R47), and tolerant Pioneer variety $25 \mathrm{R} 78$ (R78) when infested (blue) and uninfested (pink). Error bars represent standard errors of each sample. 


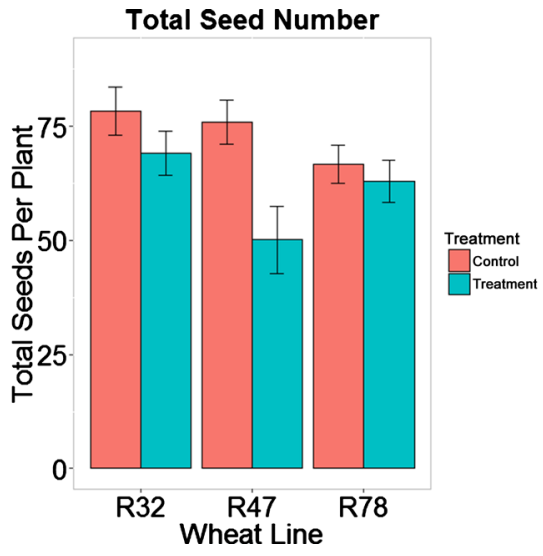

Figure 4. Relationship between total seed number per plant, wheat line, and treatment. Wheat lines: resistant 25R32 (R32), susceptible Pioneer variety 25R47 (R47), and tolerant Pioneer variety 25R78 (R78) when infested (blue) and uninfested (pink). Error bars represent standard errors of each sample.

Table 3. Post-hoc Tukey analysis on total seed number, total seed weight, average seed number, and average seed weight.

\begin{tabular}{ccc}
\hline Measurement & Wheat Line & P value \\
\hline Total Seed Number & $25 \mathrm{R} 78-25 \mathrm{R} 47$ & 0.933 \\
& $25 \mathrm{R} 78-25 \mathrm{R} 32$ & 0.492 \\
Total Seed Weight & $25 \mathrm{R} 78-25 \mathrm{R} 47$ & 0.999 \\
& $25 \mathrm{R} 78-25 \mathrm{R} 32$ & 0.681 \\
Average Seed Number & $25 \mathrm{R} 78-25 \mathrm{R} 47$ & $0.018^{*}$ \\
& $25 \mathrm{R} 78-25 \mathrm{R} 32$ & 0.999 \\
Average Seed Weight & $25 \mathrm{R} 78-25 \mathrm{R} 47$ & 0.275 \\
& $25 \mathrm{R} 78-25 \mathrm{R} 32$ & 0.729 \\
\hline
\end{tabular}

${ }^{*}$ Significant at $\mathrm{P} \leq 0.05 .{ }^{*}$ Significant at $\mathrm{P} \leq 0.01 .{ }^{* *}$ Significant at $\mathrm{P} \leq 0.001$.

Hessian fly infestation did not significantly decrease total seed weight for resistant or tolerant plants $(P=0.450$ and $P=0.960$, respectively; Figure 5). However, infested susceptible Pioneer variety 25R47 was significantly smaller than the uninfested plants $(P=0.003)$. There was no significant difference in total seed number between infested tolerant plants and infested Pioneer variety 25R32 plants or infested Pioneer variety 25R47 plants $(\mathrm{P}=0.999$ and $\mathrm{P}=0.681$, respectively) (Table 4).

\subsection{Average Seed Number and Weight}

Hessian fly infestation did not significantly decrease average seed number for resistant, tolerant, or susceptible plants $(\mathrm{P}=0.997, \mathrm{P}=0.991$, and $\mathrm{P}=0.999$, respectively; Figure 6). Infested tolerant plants showed significantly more seeds than infested Pioneer 25R47 plants $(\mathrm{P}=0.018)$. There was no significant difference between average seed numbers of infested tolerant and resistant plants $(\mathrm{P}=$ 0.999). Hessian fly infestation did not significantly decrease average seed weight 
for resistant, tolerant, or susceptible plants $(\mathrm{P}=0.999, \mathrm{P}=0.992$, and $\mathrm{P}=0.980$, respectively; Figure 7). There was no significant difference between average seed weights of infested tolerant and resistant plants $(\mathrm{P}=0.729)$ or susceptible plants $(\mathrm{P}=0.275)$.

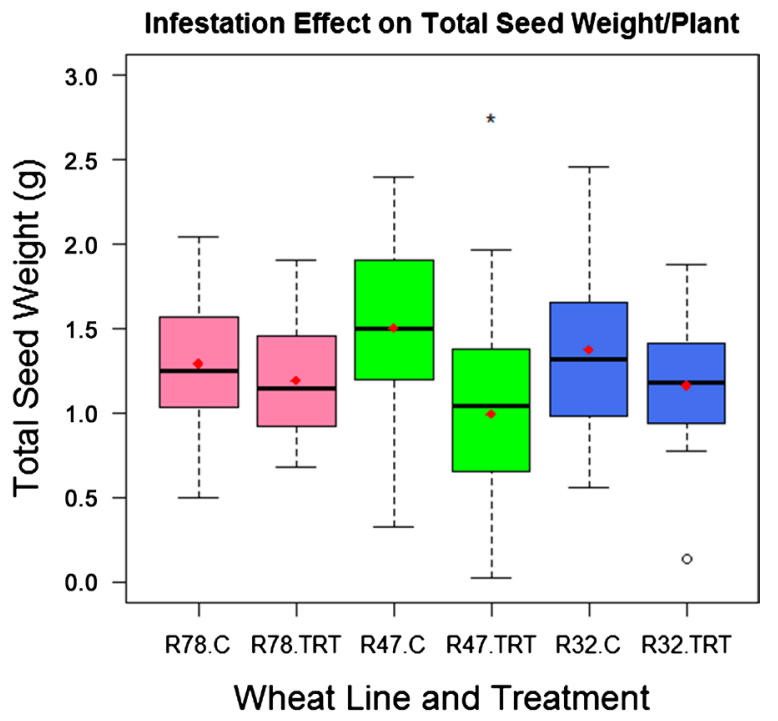

Figure 5. Relationship between the total seed weight per plant, wheat line, and treatment. Treatments where total seed weight per plant means differ significantly $(\mathrm{P}<0.05)$ from their corresponding controls are indicated by a black asterisk. The box plot highlights the sample mean (red dot), median (thick dark line), first and third quartiles (lower and upper edges), and minimum and maximum (lower and upper range bars). Possible outliers in a sample are indicated by the open circles.

Table 4. Effects of treatment and wheat line, and their interaction on the total number and weight of seeds and the average number and weight of seeds as determined by two-way ANOVA.

\begin{tabular}{ccccccc}
\hline & & F-value & Df & P-value & Sum Sq. & Mean Sq. \\
\hline Total Seed & Treatment & 9.400 & 1.142 & $0.003^{* *}$ & 5029 & 5029 \\
Number & Line & 2.426 & 2.142 & 0.092 & 2595 & 1298 \\
& Treatment:Line & 2.703 & 2.142 & 0.070 & 2892 & 1446 \\
Average Seed & Treatment & 0.040 & 1.142 & 0.842 & 0.600 & 0.650 \\
Number & Line & 13.82 & 2.142 & $<0.001^{\star * *}$ & 451.5 & 225.8 \\
& Treatment:Line & 0.095 & 2.142 & 0.910 & 3.100 & 1.550 \\
Total Seed & Treatment & 13.42 & 1.142 & $<0.001^{\star * *}$ & 2.471 & 2.471 \\
Weight (g) & Line & 0.069 & 2.142 & 0.933 & 0.025 & 0.013 \\
& Treatment:Line & 2.638 & 2.142 & 0.075 & 0.972 & 0.486 \\
& Treatment & 0.181 & 1.142 & 0.672 & 0.002 & 0.002 \\
Average Seed & Line & 5.776 & 2.142 & $<0.001^{* * *}$ & 0.117 & 0.058 \\
Weight (g) & Treatment:Line & 0.009 & 2.142 & 0.991 & 0.000 & 0.000 \\
\hline
\end{tabular}

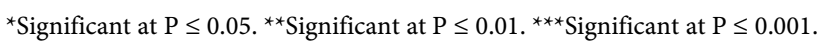




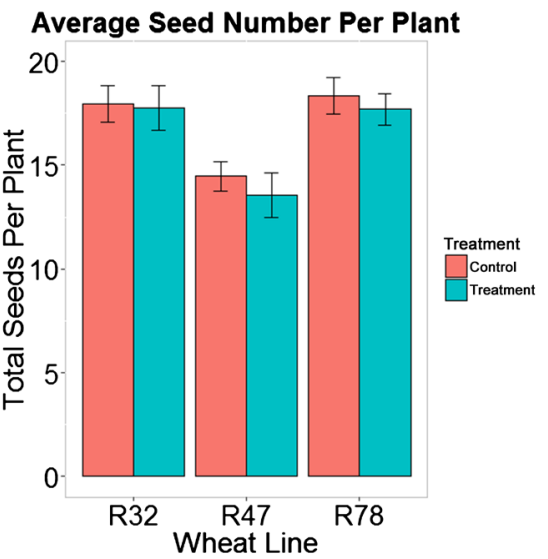

Figure 6. Relationship between average seed number per plant, wheat line, and treatment. Wheat lines: resistant 25R32 (R32), susceptible Pioneer variety 25R47 (R47), and tolerant Pioneer variety 25R78 (R78) when infested (blue) and uninfested (pink). Error bars represent standard errors of each sample.

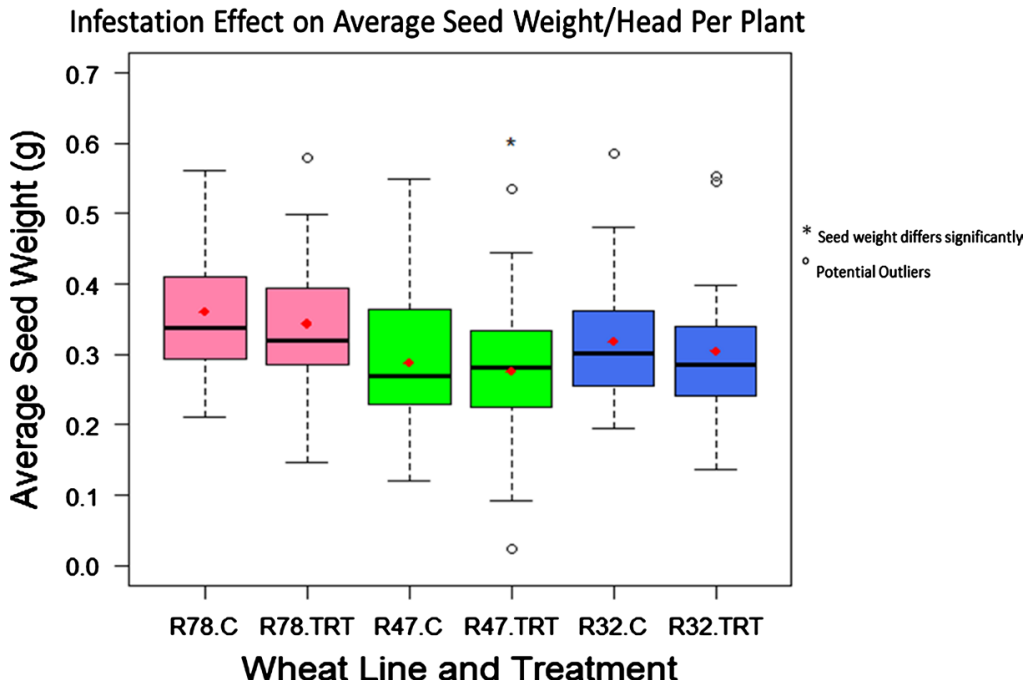

Figure 7. Relationship between the average seed weight per plant, wheat line, and treatment. Treatments where average seed weights per plant means differ significantly $(\mathrm{P}<$ 0.05) from their corresponding controls are indicated by a black asterisk. The box plot highlights the sample mean (red dot), median (thick dark line), first and third quartiles (lower and upper edges), and minimum and maximum (lower and upper range bars). Possible outliers in a sample are indicated by the open circles.

\subsection{Plant Survival}

There is no evidence that plant survival depends on wheat line and infestation $\left(\chi^{2}=7, d f=5, P=0.221\right)$. The only wheat line that showed plant death was susceptible Pioneer variety 25R47 when infested. Ten infested susceptible plants died while no other plants died. However, this was not significantly different from the other lines and treatment.

\section{Discussion}

Managing Hessian fly infestations has been a challenge, focusing efforts on 
wheat resistance genes as a control method. While effective temporarily, selection pressures lead to Hessian fly populations overcoming resistant plants. This leads to the problem of finding other ways to improve longevity of resistance genes while also providing a method for plants to produce yield despite successful larval attack. One of these potential methods might be using tolerant wheat lines to produce yield without killing larvae. In this experiment, infestation in tolerant plants had no permanent yield effects, like infested resistant plants. Both tolerant and resistant plants showed no significant differences for head number, fertile head number, tiller number, total seed number, total seed weight, average seed number, and average seed weight, regardless of infestation or not. The same patterns occurred between infested and uninfested resistant plants.

Like tolerant and resistant plants, susceptible plants showed no significant differences in average seed weight or average seed number. However, susceptible plants did show significant yield effects, where infested susceptible plants had significantly fewer heads, fertile heads, total seed number, total seed weight, and tillers. The measurements that showed significant differences for the susceptible plants were those used in a previous study investigating fitness costs of plant resistance [25]. That study analyzed fitness costs for $\mathrm{H}$-gene mediated resistance by looking at yield effects of infestation [25]. Although this experiment was focused on yield effects in tolerant plants and not fitness costs, the measurements are a useful tool for looking at yield loss. With the results, it was clear that infestation reduced the yield of the susceptible plants, but not the tolerant or resistant plants.

There were no larval effects on tiller number for tolerant and resistant plants and negative effects on tiller number for susceptible plants (Table 4). The number of tillers per plant is one of the primary contributors to wheat grain yield [26] [27]. Due to this connection between tiller number and grain yield, tiller loss from Hessian fly infestation could reduce yield. In the case of tolerant Pioneer variety 25R78, the prevention of tiller loss might prevent yield loss, making the tolerant line more economically appealing to farmers. Also, infestation does not reduce seed production through seed number or seed weight per head. Each of the infested lines showed no significant differences in total seed number or total seed weight compared to the corresponding uninfested plants. This indicates that this measurement of yield showed no adverse effects from infestation, regardless of wheat line.

No negative effects of infestation were observed for the average seed number or weight per head for any line. These results indicate that larval attack does not reduce these measurements, only the number of heads and total seed number. This varies from the results of Anderson and Harris [25], in which the susceptible line "Newton" demonstrated a negative larval effect on the average seeds per plant. The absence of larval effects on seed number is important for yield. More seeds could result in a greater yield per plant and per hectare.

Infested susceptible Pioneer variety $25 \mathrm{R} 47$ was the only line and treatment to have any dead plants with ten plants. However, plant survival was not dependent 
on wheat line and treatment $(\mathrm{P}=0.221)$. These results indicate the ability of tolerant plants to prevent death caused by larval attack, reacting more like resistant rather than susceptible plants.

The absence of significant yield effects from Hessian flies on tolerant wheat demonstrates the potential for tolerant lines to be used in solely tolerant or mixed fields with resistant wheat. Evidence shows that tolerant wheat has the potential to be used as a stand-alone crop due to the ability of the line to survive infestation and produce yield. Tolerant lines could also be used in fields mixed with a resistant line to act as a refuge crop.

\section{Conclusions}

The yield measurements, including the primary contributors, tiller number, seed number, and seed weight, showed no significant negative effects from infestation in the tolerant wheat plants. The tolerant plants also showed no significant growth effect from infestation on head number, fertile head number, total seed number and weight, and average seed number and weight. There was no significant yield loss for infested tolerant plants and these plants showed similar results in yield measurements compared to infested resistant plants.

Overall, the results indicate that tolerant Pioneer wheat variety $25 \mathrm{R} 78$ appears to have the ability overcome infestation with no negative effects on yield and plant survival, like that of resistant plants. This, along with the possibility of the absence of selection pressure on fly populations, could make tolerance a useful method of Hessian fly control.

\section{Acknowledgements}

We would like to thank Sue Cambron and Richard Smith for greenhouse assistance. We would like to thank Greg Marshall at Dupont Pioneer for providing seeds.

This work is a joint contribution of the USDA-ARS and Purdue University. It was supported through USDA-ARS Research Project number 5020-22000-019-00D. Mention of a commercial or proprietary product does not constitute an endorsement by the USDA. The funding body has no role in the design of the study and collection, analysis and interpretation of data and in writing the manuscript.

\section{Conflicts of Interest}

The authors declare no conflicts of interest regarding the publication of this paper.

\section{References}

[1] Fisher, R.A. (2009) Foreword. In: Carver, B.F., Ed., Wheat Science and Trade, Wiley-Blackwell, Ames, IA, xvii.

[2] Cartwright, W.B. and Jones, E.T. (1953) The Hessian Fly and How Losses from It 
Can Be Avoided. USDA Farmers' Bulletin, 162, 1-9.

[3] Barnes, H.F. (1956) Gall Midges of Economic Importance. Vol. VII: Gall Midges of Cereal Crops. Crosby Lockwood \& Son, London.

[4] El Bouhssini, M., Lhaloui, S., Amri, A., Jlibene, M., Hatchett, J.H., Nssarellah, N. and Nachitt, M. (1996) Wheat Genetic Control of Hessian Fly (Diptera: Cecidomyiidae) in Morocco. Field Crops Research, 45, 111-114. https://doi.org/10.1016/0378-4290(95)00063-1

[5] Harris, M.O., Stuart, J.J., Mohan, M., Nair, S., Lamb, R.J. and Rohfritsch, O. (2003) Grasses and Gall Midges: Plant Defense and Insect Adaptation. Annual Review of Entomology, 48, 549-577. https://doi.org/10.1146/annurev.ento.48.091801.112559

[6] Amri, A., El Bouhssini, M., Lhaloui, S., Cox, T.S. and Hatchett, J.H. (1992) Estimates of Yield Loss due to Hessian Fly (Diptera: Cecidomyiidae) on Bread Wheat Using Near-Isogenic Lines. Al Awamia, 77, 75-87.

[7] Lhaloui, S., Buschman, L., El Bouhssini, M., Starks, K., Keith, D. and El Houssaini, K. (1992) Control of Mayetiola Species (Diptera: Cecidomyiidae) with Carbofuran in Bread Wheat, Durum Wheat, and Barley, with Yield Loss Assessment and Its Economic Analysis. Al Awamia, 77, 55-73.

[8] Gallun, R.L. and Langston, R. (1963) Feeding Habits of Hessian Fly Larvae on $\mathrm{P}^{32}$-Labelled Resistant and Susceptible Wheat Seedlings. Journal of Economic Entomology, 56, 702-706. https://doi.org/10.1093/jee/56.5.702

[9] Gagne, R. and Hatchett, J.H. (1989) Instars of the Hessian Fly. Annals of the Entomological Society of America, 82, 73-79. https://doi.org/10.1093/aesa/82.1.73

[10] Harris, M.O., Freeman, T.P., Rohfritsch, O., Anderson, K.G., Payne, S.A. and Moore, J.A. (2006) Virulent Hessian Fly (Diptera: Cecidomyiidae) Larvae Induce a Nutritive Tissue during Compatible Interactions with Wheat. Annals of the Entomological Society of America, 99, 305-316. https://doi.org/10.1603/0013-8746(2006)099[0305:VHFDCL]2.0.CO;2

[11] Buntin, G. and Chapin, J.W. (1990) Biology of Hessian Fly (Diptera: Cecidomyiidae) in the Southeastern United States: Geographic Variation and Temperature-Dependent Phenology. Journal of Economic Entomology, 83, 1015-1024. https://doi.org/10.1093/jee/83.3.1015

[12] Buntin, G.D. (1999) Hessian Fly (Diptera: Cecidomyiidae) Injury and Loss of Winter Wheat Grain Yield and Quality. Journal of Economic Entomology, 92, 1190-1197. https://doi.org/10.1093/jee/92.5.1190

[13] Agrios, G.N. (1997) Plant Diseases Caused by Mollicutes: Phytoplasmas and Spiroplasmas. In: Agrios, G.N., Ed., Plant Pathology, Academic Press, New York, 457-470.

[14] Ratcliffe, R.H. and Hatchett, J.H. (1997) Biology and Genetics of the Hessian Fly and Resistance in Wheat. In: Bondarie, K., Ed., New Developments in Entomology, Research Signpost, Scientific Information Guild, Trivandrum, India, 47-56.

[15] Shukle, R.H., Grover, P.B. and Foster, J.E. (1990) Feeding of Hessian Fly (Diptera: Cecidomyiidae) Larvae on Resistant and Susceptible Wheat. Environmental Entomology, 19, 494-500. https://doi.org/10.1093/ee/19.3.494

[16] Li, C., Chen, M., Chao, S., Yu, J. and Bai, G. (2013) Identification of a Novel Gene, H34, in Wheat Using Recombinant Inbred Lines and Single Nucleotide Polymorphism Markers. Theoretical and Applied Genetics, 8, 2065-2071.

https://doi.org/10.1007/s00122-013-2118-5

[17] McDonald, M., Ohm, H., Rinehart, K., Giovanini, M. and Williams, C. (2014) H33: A Wheat Gene Providing Hessian Fly Resistance for the Southeastern United States. 
Crop Science, 54, 2045-2053. https://doi.org/10.2135/cropsci2013.12.0811

[18] Sardesai, N., Nemacheck, J., Subramanyam, S. and Williams, C.E. (2005) Identification and Mapping of H32, a New Wheat Gene Conferring Resistance to Hessian Fly. Theoretical and Applied Genetics, 111, 1167-1173. https://doi.org/10.1007/s00122-005-0048-6

[19] Smedegaard-Paterson, V. and Stølen, O. (1980) Effect of Energy-Requiring Defense Reactions on Yield and Grain Quality in a Powdery Mildew-Resistant Barley Cultivar. Phytopathology, 71, 396-399. https://doi.org/10.1094/Phyto-71-396

[20] Reese, J., Schwenke, J., Lamont, P. and Zehr, D. (1994) Importance and Quantification of Plant Tolerance in Crop Pest Management Programs for Aphids: Greenbug Resistance in Sorghum. Journal of Agricultural Entomology, 11, 255-270.

[21] Strauss, S. and Agrawal, A. (1999) The Ecology and Evolution of Plant Tolerance to Herbivory. Trends in Ecology \& Evolution, 14, 179-185. https://doi.org/10.1016/S0169-5347(98)01576-6

[22] Painter, R.H. (1951) Insect Resistance in Crop Plants. Macmillan, New York. https://doi.org/10.1097/00010694-195112000-00015

[23] R Core Team (2014) R: A Language and Environment for Statistical Computing. R Foundation for Statistical Computing. Vienna, Austria. http://www.R-project.org/

[24] Wise, I.L., Lamb, R.J., McKenzie, R.I.H. and Whistlecraft, J.W. (2006) Resistance to Hessian Fly (Diptera: Cecidomyiidae) in a Canadian Spring Wheat Cultivar. The Canadian Entomologist, 138, 638-646. https://doi.org/10.4039/n05-051

[25] Anderson, K.M., Kang, Q., Reber, J. and Harris, M.O. (2011) No Fitness Cost for Wheat's $H$ Gene-Mediated Resistance to Hessian Fly (Diptera: Cecidomyiidae). Journal of Economic Entomology, 104, 1393-1405. https://doi.org/10.1603/EC11004

[26] Chowdhry, M.A., Ali, M., Subhani, G.M. and Khaliq, I. (2000) Path Coefficient Analysis for Water Use Efficiency, Evapo-Transpiration Efficiency, Transpiration Efficiency and Some Yield Related Traits in Wheat. Pakistan Journal of Biological Sciences, 3, 313-317. https://doi.org/10.3923/pjbs.2000.313.317

[27] Gupta, A.K., Mittal, R.K. and Ziauddin, A. (1999) Association and Factor Analysis in Spring Wheat. Annals of Agricultural Sciences, 20, 481-485. 